\title{
$\nsim$ CORRESPONDENCE
}

Carbon monoxide yield of cigarettes

K P Ball, FRCP.............. 731

Self-titration by cigarette smokers

R G Rawbone, MB.............. 731

Alcohol-dependent doctors

M M Glatt, FRCP............ 732

Tetraplegia caused by gymnastics

R F Evans, FrCs............... 732

Nutritional standards and saving money on school meals

A E Bender, PHD ............. 732

Care of children in general practice

G H Curtis Jenkins, MB........... 733

Referral of mothers and infants for

intensive care

M L Chiswick, MD............ 733

Breast or bottle

D W Hide, MRCPED; Helen J Graham, MB;

Carolyn Jones, PHD............ 733

Fetal malnutrition - the price of

upright posture?

A Briend, $M D \ldots \ldots \ldots \ldots \ldots . \ldots . \ldots 74$
Hats for the newborn infant

E C Coles, MB, and H B Valman, FRCP... 734

Kidney transplants and long-term

immunosuppression

B Jones, mB................ 735

Reactions to whooping cough vaccine

J S Robertson, FFCM . . . . . . . . . . . . . 735

Rubella vaccination

N A Black, MB; T S Wilson, FFCM . . . . . . 735

Effects of manufacturing oral

contraceptives on blood clotting

L Poller, FRCPATH, and others. . . . . . . . 735

Serum bilirubin and hepatic enzyme induction

B F Allam, MB . . . . . . . . . . . 736

Volunteer and professional treatments

of dysphasia after stroke

B O Williams, MRCP, and Sandra A Walker,

LCST; Margaret S Meikle, LCST, and Enid

Wechsler, LCST............... 736

Cubital tunnel syndrome

T G Wadsworth, FRCs........... 736
Dangerous antihypertensive treatment Priscilla S Kincaid-Smith, FRCP; J A E Primrose, FRCSED.............. 737

Medicine and the media

W J Elwood, MFCM............... 737

General practice in hospital accident and

emergency departments

Major P J Gravett, MRCPATH......... 737

Fenclofenac-induced nephrotic

syndrome?

J S H Gaston, BM, and P A Dieppe, MRCP. . 738

Psychosocial stress in pregnancy

M O Roland, MRCP............. 738

Spread of steroid-containing foam after

intrarectal administration

M H Irving, FRCs; V T Kelly . . . . . . . . . 738

Design of forms for clinical trials

E A Benson, Frcs. . . . . . . . . . . . . 738

General anaesthesia in sickle-cell disease

J Homi, FFARCS................ 739

Who wants to sit on the GM̈

Sir Graham M Bull, FRCP........... 739

Pre-employment medicals

W Norman-Taylor, mD ........... 739 \section{7} 37 38 738 8 39

We may return unduly long letters to the author for shortening so that we can offer readers as wide a selection as possible. We receive so many letters each week that we have to omit some of them. Letters must be signed personally by all their authors. We cannot acknowledge their receipt unless a stamped addressed envelope or an international reply coupon is enclosed.

\section{Carbon monoxide yield of cigarettes}

SIR,-For the past 10 years evidence has been growing that carbon monoxide $(\mathrm{CO})$ is an important health hazard for smokers. Mainstream cigarette smoke contains from $2^{\circ}$ to $6 \%$ of carbon monoxide and when inhaled and diluted with air it may contain about 400 parts per million of $\mathrm{CO}$, which is eight times greater than the maximum level permitted in industry. Although filter cigarettes tend to have lower tar levels than plain brands, their $\mathrm{CO}$ levels may be higher (if the filters are not ventilated).$^{1-3}$

The reduction of mean tar levels associated with the increase of filter cigarettes in recent years may well have contributed to a fall in lung cancer rates in men under the age of 60 . But the higher CO levels may have led to more deaths from coronary heart disease. Knowledge of carbon monoxide yields is therefore very important. It could also be of value for a patient with coronary heart disease who is unable to stop smoking to smoke a cigarette with a lower $\mathrm{CO}$ rather than a lower tar yield. However, the doctor wishing to advise him is at present unable to do so.

Until now the Government has been unwilling to publish the $\mathrm{CO}$ yields of individual brands of cigarettes, although it is known that they are measured by the Government Chemist. Is the DHSS concerned that the tar and nicotine tables would be too complicated with the addition of $\mathrm{CO}$ levels ? Or is it unwilling to embarrass the industry with the approaching negotiations on "the voluntary agreement" which the industry had with the last Government?

There seem to be no good reasons for withholding information from the profession and anyone else who wishes to know. Publication would have the added advantage of stimulating the industry to lower $\mathrm{CO}$ yields of cigarettes in the same way that tar levels were reduced after the first publication of tar tables. It would also follow the recommendations of the recent WHO report. ${ }^{4}$

\section{Department of Community Medicine,
Middlesex Hospital Medical School,}

Central Middlesex Hospital,

${ }_{1}^{1}$ Russell, M A H, British Medical fournal, 1975, 3, 71. 2 Wald, N J, Lancet, 1976, 1, 136.

Copeland, G K E, paper presented at Fourth World

- Conference on Smoking and Health, June 1979.

Controlling the Smoking Epidemic. Geneva, World Controlling the Smoking E
Health Organisation, 1979 .

\section{Self-titration by cigarette smokers}

SIR,-Dr Heather Ashton and others (11 August, p 357) present results to show selftitration by smokers when they switch from smoking a middle-tar cigarette to either a hightar cigarette or a low-tar cigarette. In that they have employed a wide variety of measurement techniques in a well-balanced study and have shown titration downwards when switching to a higher-tar product (was this passed by an ethical committee ?) their study is interesting. However, the evidence that smokers attempt to compensate for reduced smoke components when switched to a lower-tar product, although admittedly to varying degrees, is consistent throughout all published studies-including our own, ${ }^{1-3}$ in which we demonstrated puff volume, and probably inhalation, to be the important variables. Furthermore, the study by Freedman and Fletcher, ${ }^{2}$ which is quoted as suggesting that smokers "can adapt without compensation to a moderate reduction in nicotine yield" in fact did, on reanalysis of their data, ${ }^{3}$ show that compensation was taking place.

Like other studies in the literature this is another short-term switching study, the measurements reported all being made during the first two weeks following the switch; and the results may be confounded by the fact that the authors have combined results from their two groups-thus mixing, for each analysis, subjects switching from middle-tar control to test product and subjects switching between the two test products.

It seems clear that when subjects switch to a lower-tar product they attempt compensation, but whether this is for the pharmacological effect of nicotine (or any other smoke constituent) or simply because of the reduced impact and flavour of the lower-tar product is an unanswered (and possibly unanswerable) question. What is important is that despite the attempted compensation the intake of nicotine, carbon monoxide, and, by inference, tar is still less than when they were smoking the higher tar product.

What is required is a long-term study of several years' duration to show whether the attempted compensation after switching to lower-tar products persists and, if so, to what extent. Our own published observations, ${ }^{1}$ made on subjects who had smoked either middle-tar or low-tar products for at least two years, would suggest that the compensation does not persist in that the intake of smoke 
constituents in the two groups was in exact proportion to the machine-smoked yields of the two types of product. This means that any long-term benefits from switching to a low-tar cigarette are better than the hitherto published short-term switching studies would suggestprovided that any dose-response relationship between "disease" and "tar" intake regresses toward zero, and cigarette consumption does not increase.

\section{ROGER G RAWBONE}

Department of Medicine,

Charing Cross Hospital (Fulham),
London W6 8RF ' Rawbone, R G, et al, in Smoking Behaviour: Physio-
logical and Psychological Influences, ed R E Thornon. Edinburgh, Churchill Livingstone, 1978

${ }^{2}$ Freedman, S, and Fletcher, C M, British Medical fournal, 1976, 1, 1427

Rawbone, R G, British Medical fournal, 1976, 2, 177.

\section{Alcohol-dependent doctors}

SIR,-The high susceptibility of doctors to alcoholism (leading article, 11 August, p 351) is reflected in the findings of a fairly steady percentage of $2-4 \%$ of doctors among male alcoholic admissions to the alcoholic units at Warlingham Park Hospital and St Bernard's Hospital over a 25-year period (1952-77). ${ }^{12}$

Unfortunately, as you say in your editorial, most alcoholic doctors present late for treatmen and usually only under considerable pressure from their families, their medical partners, etc. Yet when treated in a therapeutic community they more often than not prove very co-operative patients, participating actively in treatment, taking a leading role in helping fellow patients, and showing an active interest in follow-up activities they only rarely discharge themselves prematurely against advice, and their prognosis is by no mean bad. ${ }^{2}$ One of the most hopeful developments in this field in this country (as in the USA) has been the formation, over five years ago, of the British Doctors Group for recovering alcoholics.

A questionnaire survey recently undertaken by members of the group elicited 59 replies $(50 \%)$ from 120 doctors to whom the questionnaire had been mailed. ${ }^{3}$ The replies indicated that, out of 56 returning fully completed questionnaires, 37 doctors had been "sober" (that is, fully abstaining from alcohol and psychotropic drugs) for a mean period of 4.1 (range $1-26$ ) years. O these 37 doctors, $28(76 \%)$ stated that they had in the past tried, unsuccessfully, to control thei drinking. Thirty-one $(84 \%)$ had received inpatien treatment at some stage, $20(54 \%)$ of them in an alcoholism treatment unit. With two exception among the 37 doctors, the great majority regularly attended either Alcoholics Anonymous meetings or local after-care facilities, or both.

In theory there is no reason why prognosis in the case of alcoholic doctors should not be reasonably good, once they can be motivated to face up to their problems. Prognosis in alcoholism depends mainly on emotional and social stability of the personality; the majority of medical men surely have a relatively stable personality, and it is probably largely environmental rather than emotional factors which are responsible for the majority of cases of alcoholism among medical men. Continual excessive emotional and physical demands, frustrations, the need to relax after working hours, etc. may prompt many doctors to rely more and more on the familiar comforter of their student days. ${ }^{1}$ Education about alcohol problems is the more important for medical students for many of whom unfortunately medical schools often appear to be "excellent training grounds for the drinking habit."4 But in general doctors have been taught so little about the early stages of alcoholism that many still do not suspect the condition until they are confronted with its physical complications; and quite a few alcoholic doctors tell one that they had felt they could not possibly be alcoholics because, after all, they were not spending most of their days dead drunk in the gutter.

The outcome of the still-prevailing laisserfaire attitude to education and the early diagnosis and treatment of alcoholic doctors will be many more avoidable cases of dead doctors and perhaps also dead patients. Alcoholism is, or should be, to a large extent a preventable disorder particularly among doctors. From our own experiences in the teaching of medical students about the early stage of alcoholism over the past 20 years, it would seem that such teaching should present no difficulties and that students quickly begin to take an interest in this increasing sociomedical problem and its victims.

M M Glatt

\section{University College Hospital \\ Alcoholism Outpatient (Teaching) \\ Centre, \\ St Pancras Hospital}

' Glatt, M M, British Medical fournal, 1977, 1, 507.

2 Glatt, M M, Lancet, 1974, 2,342 .

'British Doctors' Group, 1979, personal communica-

- Fox, R A, Lancet, 1978, 2, 731

\section{Tetraplegia caused by gymnastics}

SIR,-Within a period of a month two teenage girls have been admitted under my care with fracture dislocations of the cervical spine resulting in tetraplegia. Both injuries had been caused while the girls were participating in gymnastics. The first, aged 13, suffered her neck injury while trampolining; and the second, aged 14, while practising asymmetrical bar exercises to take part in first-class competition.

These are otherwise rare injuries and I wonder whether these tragic accidents are chance occurrences or the first of a trend brought about by the great interest taken in gymnastics by young girls at present. I would be interested to know if any of your readers have had similar experiences.

Birmingham Accident Hospital, Birmingham B15 1NA

Nutritional standards and saving money on school meals

SIR,-There is much current discussion on the possibility of saving public money from the education budget by changes in school meals and questions have been raised about lowering the nutritional standards. One suggestion is that savings may result from altering the type of meal from the traditional "meat-and-two-veg" to sandwiches and soup. In measuring any change in nutritional content one question is whether we are using the standards laid down by the Department of Education and Science or comparing the meals with what is currently being supplied to the children.

Nutritional guidelines state that children in each age group should be served with a minimum of one-third of their recommended daily intake of energy and $42 \%$ (between one-third and a half of their recommended daily intake of protein. This would result in the targets shown in table I However, a thorough examination of 12 schools in one area ${ }^{2}$ showed that this target was almost neve reached (table I). For the younger children, presumably those at greatest risk, the amount of food supplied (energy) reached only two-thirds
TABLE I-Nutritional targets and achievements in school meals ${ }^{2}$

\begin{tabular}{lccccc}
\hline & \multicolumn{2}{c}{ Energy } & & \multicolumn{2}{c}{ Protein } \\
\cline { 2 - 3 } \cline { 5 - 6 } Type of school & $\begin{array}{c}\text { Target } \\
\left(\mathbf{M J}^{*}\right)\end{array}$ & $\begin{array}{c}\text { Achieve- } \\
\text { ment } \\
(\%)\end{array}$ & & $\begin{array}{c}\text { Target } \\
(\mathrm{g})\end{array}$ & $\begin{array}{c}\text { Achieve- } \\
\text { ment } \\
(\%)\end{array}$ \\
\hline Infant & 2.5 & 65 & & 19 & 76 \\
Infant and Junior & 2.9 & 76 & 22 & 77 \\
Junior & 3.1 & 70 & & 23 & 74 \\
Middle & 3.6 & 86 & & 27 & 81 \\
Senior & 3.7 & 95 & & 28 & 86 \\
\hline
\end{tabular}

$* 1 \mathrm{MJ} \approx 239 \mathrm{kcal}$.

of that recommended-and this without taking into consideration any left on the plate.

Similar figures were obtained in an earlier cross-sectional survey of 48 schools. $^{3}$ This used the guidelines suggested at that time, which were not very different from current recommendations, although not stated so precisely and therefore open to various interpretations by the caterers in charge of menu planning and purchasing.

These figures showed that $63-75 \%$ of the energy target and $55-61 \%$ of the protein target were achieved in various age groups. Another survey ${ }^{4}$ showed similar shortfalls. These meals were very varied in composition but basically of the traditional pattern of meat with two vegetables or fish and chips or salads, followed by puddings of various types (often rich in sugar).

Now the problem arises when we consider whether snack meals or sandwiches will result in a reduction of energy and nutrients supplied. Do we use the recommended guidelines or the amounts that are in practice being supplied (at least in three areas)?

Soups and sandwiches can be of many types, depending on the skill of the mother or caterer who is supplying them; but for the purposes of comparison we could take a lentil soup as analysed in the standard food tables ${ }^{5}$ and cheese and bread (amounts would obviously vary with thickness, etc). Table II shows that this can be as good as any traditional type of meal. If sandwiches and soup are cheaper to provide, then there is no need to change nutritional guidelines.

TABLE II-Energy and protein content of soup and sandwiches

\begin{tabular}{ccc}
\hline & $\begin{array}{c}\text { Energy } \\
\left(\mathrm{MJ}^{*}\right)\end{array}$ & $\begin{array}{c}\text { Protein } \\
(\mathrm{g})\end{array}$ \\
\hline Two cheese sandwiches & & \\
Bread $(4$ slices $=100 \mathrm{~g})$ & 1.0 & 8 \\
Cheese $(1 \mathrm{oz}=30 \mathrm{~g})$ & 0.6 & 8 \\
Lentil soup (7 f oz $=200 \mathrm{~g})$ & 0.8 & $\frac{9}{25}$ \\
Total & $\overline{2 \cdot 4}$ & 2.4
\end{tabular}

*1 $\mathrm{MJ} \approx 239 \mathrm{kcal}$.

Guidelines are not laid down for other nutrients but should reach one third of the recommended daily intake. Our first survey ${ }^{3}$ showed that the meals offered supplied 2.3 to $4.3 \mathrm{mg}$ iron and $160-200 \mathrm{mg}$ calcium, and included $20-25 \mathrm{~g}$ sugar (one particular meal supplied $80 \mathrm{~g}$ of sugar $(1 \cdot 3 \mathrm{MJ}$; $320 \mathrm{kcal}$ ), or about $40 \%$ of the energy target for the entire meal). Our second survey ${ }^{2}$ showed adequate supply of nutrients-38-75\% of the total daily recommended intake of vitamin $C$ $16-30 \%$ thiamin, $24-29 \%$ iron, and $26-49 \%$ calcium. These figures were calculated and analysed figures were much lower for vitamin C. What is often lost sight of is that individuals, including children, vary enormously in their energy needs, and while this is taken care of to some extent in some schools by offering "seconds" or different sizes of portions this is not true of al schools that we examined-in some areas second helpings were not permitted and in others the same quantity was provided whatever size was requested. In view of these differences in requirements, not to mention daily fluctuations in appetite, it is possible that a cafeteria type of service offering a choice of foods and portions may be helpful, apart from any saving in staff. 